\title{
UMA ANÁlise HERMENÊUTICA DOS AVANÇOS TRAZIDOS PELO NOVO CPC
}

\author{
LENIO LUIZ STRECK ${ }^{\dagger}$
}

RESUMO: Nunca estive de má vontade com o CPC/15. Tudo o que escrevi foi para criticar o instrumentalismo processual e seus efeitos colaterais, presentes até que o Relator, Dep. Paulo Teixeira, assumisse, corajosamente, a tese de que havia algo a mais para ser tratado no Projeto. Esse plus dizia respeito aos paradigmas filosóficos e à necessidade de controlar as decisões judiciais. De todo modo, creio que do projeto e sua complexidade podem ser retirados alguns princípios norteadores do novo Código, como o da necessidade de manter a coerência e a integridade da jurisprudência (incluídos os precedentes), a vedação do livre convencimento, o que implica um menor protagonismo e a necessidade da adoção do paradigma da intersubjetividade, ou seja, a subjetividade do juiz deve ser suspensa e controlada pela intersubjetividade estruturante do direito. Essa é a holding do novo "sistema". Sem compreendê-lo, corremos o risco de fazer uma revolução à avessas. Raciocínios pequeno-gnosiológicos ainda assentados nos paradigmas objetivistas ou subjetivistas (ou de suas vulgatas voluntaristas) podem, rapidamente, provocar a derrocada de uma boa ideia.

PAlavRAS-ChaVe: Hermenêutica Jurídica; Novo CPC; Decisão Judicial; Livre Convencimento; Precedentes.

\footnotetext{
† Professor Titular do Programa de Pós-Graduação em Direito da Unisinos, RS, e Unesa, RJ. Doutor e Pós-Doutor em Direito. Ex-Procurador de Justiça (MP/RS). Membro Catedrático da Academia Brasileira de Direito Constitucional - ABDCONST. Professor Emérito da EMERJ/RJ. Presidente de Honra do Instituto de Hermenêutica Jurídica (IHJ). Advogado.
} 
ABSTRACT: I've never been unwillingly with CPC/15. Everything I wrote to criticize the procedural instrumentalism and its side effects, present until the Rapporteur, Deputy Paulo Teixeira, assumed courageously the thesis that there was something more to be treated in the Project. This plus concerned the philosophical paradigms and the need to control the judicial decisions. Anyway, I believe that some guiding principles of the new code can be drawn from the project and its complexity, such as the need to maintain the consistency and integrity of the case law (including the precedents), the prohibition of the free convincing, which implies minor role and the need to adopt the intersubjectivism paradigm, that is, the subjectivity of the judge should be suspended and controlled by structuring intersubjectivity of law. This is the holding of the new "system". Without understanding it, we run the risk of making a reverse revolution. Small-gnosiological reasoning still seated in objectivist and subjectivist paradigm (or its voluntarist vulgatas) can quickly cause the downfall of a good idea.

KeYwORDS: Legal Hermeneutics; New Civil Procedure Code; Judicial Decision; Free Convincing; Precedents. 


\section{SUMÁRIO:}

I. O NOVO E O VELHO: A RETIRADA DO LIVRE CONVENCIMENTO DO NOVO CPC

II. RUMO À SUPERAÇÃO DO VELHO MODELO SOCIAL-PROTAGONISTA? ESPERAMOS QUE SIM...............................150

III. EFETIVIDADES QUANTITATIVAS OU QUALITATIVAS?

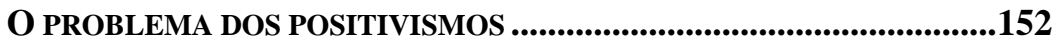

IV. SERÍAMOS UMA CORRUPTELA DO COMMON LAW? O CPC E OS "PRECEDENTES" 154

V. OS EMBARGOS DECLARATÓRIOS CONVIVERÃO COM O FIM DO "LIVRE CONVENCIMENTO"?.

VI. OS PRECEDENTES E A INCINDIBILIDADE ENTRE QUESTÃO-DE-FATO E QUESTÃO-DE-DIREITO

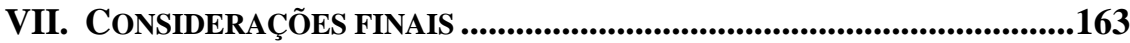

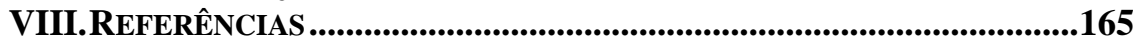

\section{TABLE OF CONTENTS:}

I. THE NEW AND THE OLD: THE WITHDRAWAL OF THE FREE CONVINCING FROM THE NEW CIVIL PROCEDURE CODE....................147

II. TOWARDS OVERCOMING THE OLD SOCIAL PROTAGONIST MODEL?

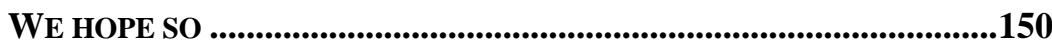

III. QUANTITATIVE OR QUALITATIVE EFFECTIVINESS? THE PROBLEM OF POSITIVISMS . .152

IV. WOULD WE BE A CORRUPTED COMMON LAW? The Civil Procedure CODE AND THE "PRECEDENTS"

V. THE DECLARATORY APPEALS WILL DEAL WITH THE END OF "FREE CONVINCING"?

VI. THE PRECEDENTS AND THE INDIVISIBILITY BETWEEN FACTUAL QUESTIONS AND LEGAL QUESTIONS ..................................161

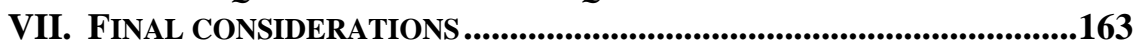

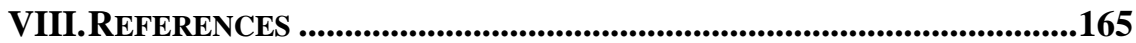




\section{O NOVO E O VELHO: A RETIRADA DO LIVRE CONVENCIMENTO DO NOVO CPC}

Quando se examina o novo $\mathrm{CPC}$, não se pode deixar de reconhecer alguns avanços consistentes. Não obstante, há de se ter muito cuidado para evitar que a própria dogmática jurídica, a partir de uma hermenêutica de bloqueio, proporcione retrocessos ao novo texto que aí vem. Como exemplo, lembremos sempre do que o Poder Judiciário fez com o art. 212 do CPP (ou seja, mesmo que o legislador tenha dito que "o juiz somente poderá fazer perguntas complementares", nem juízes, nem STJ e nem o STF levaram em conta essa inovação legislativa). Ou seja, não adianta simplesmente alterar a lei.

Travei uma batalha contra o poder discricionário, travestido de livre convencimento, que infestava o Projeto do CPC em sua redação original. Dizia eu que de nada adiantará exigir do juiz que enfrente todos os argumentos deduzidos na ação (vejam-se os artigos 499 e seguintes do Projeto) se ele tiver a liberdade de invocar a "jurisprudência do Supremo" que afirma que o juiz não está obrigado a enfrentar todas as questões arguidas pelas partes. Dá-se com uma mão e tira-se com a outra... ${ }^{1}$

De há muito venho alertando a comunidade jurídica para esse problema do protagonismo judicial, que deita raízes em uma questão paradigmática e não meramente "técnica". Veja-se, por exemplo, a seguinte decisão, que se repete nas várias instâncias da justiça brasileira:

O sistema normativo pátrio utiliza o princípio do livre convencimento motivado do juiz, o que significa dizer que o magistrado não fica preso ao formalismo da lei nem adstrito ao laudo pericial produzido nos autos, devendo o julgador analisar o caso concreto, levando em conta sua livre conviç̧ão pessoal².

E o que dizer de recente decisão do Superior Tribunal de Justiça, que "criou" um recurso, sustentado na tese da existência de "macro-lides", como pode ser visto no recente Resp. 1.251.331-RS?

Depois de muita discussão, o relator do Projeto, Dep. Paulo Teixeira,

${ }^{1}$ Cf. STRECK, Lenio Luiz. Novo CPC decreta a morte da lei. Viva o common law!

Disponível em: $<\underline{\text { http://www.conjur.com.br/2013-set-12/senso-incomum-cpc-decreta- }}$ morte-lei-viva-common-law $>$. Acesso em: 23 de maio de 2014.

2 Recurso Cível 5001367-22.2011.404.7119, Rel. Juiz Paulo Paim da Silva, 4aㅡ Turma Recursal dos Juizados Especiais Federais/RS, Julgado em 05.07.2012. 
obtendo a concordância de um dos protagonistas do Projeto, Fredie Didier, aceitou minha sugestão de retirada do livre convencimento. Considero isso uma conquista hermenêutica ${ }^{3}$ sem precedentes no campo da teoria do direito de terrae brasilis. O Projeto, até então, adotava um modelo solipsista stricto sensu, corolário do paradigma epistemológico da filosofia da consciência, bastando para tanto ler o que prescrevia art. 378:

O juiz apreciará livremente a prova constante dos autos, independentemente do sujeito que a tiver promovido, e indicará na decisão as razões da formação de seu convencimento.

Já o artigo 401 dizia que "A confissão extrajudicial será livremente apreciada pelo juiz". E no artigo 490 lia-se que "A segunda perícia não substitui a primeira, cabendo ao juiz apreciar livremente o valor de uma e outra".

Portanto, as expressões que tratavam do livre convencimento ou livre apreciação foram expungidas do Projeto 4 . A justificativa sugerida por mim e acatada, em termos gerais, pelo Deputado Relator, foi a de que:

embora historicamente os Códigos Processuais estejam

${ }^{3}$ Permito-me ser repetitivo e insistir na "questão da filosofia", embora setores importantes do direito desconsiderem o fato de a filosofia ser condição de possibilidade do próprio direito. Ainda assim, faço a seguinte observação: o que se tem visto no plano das práticas jurídicas nem de longe chega a poder ser caracterizada como "filosofia da consciência"; trata-se de uma vulgata disso. Em meus textos, tenho falado que o solipsismo judicial, o protagonismo e a prática de discricionariedades se enquadram paradigmaticamente no "paradigma epistemológico da filosofia da consciência". Advirto, porém, que é evidente que o modus decidendi não guarda estrita relação com o "sujeito da modernidade" ou até mesmo com o "solipsismo kantiano". Esses são muito mais complexos. Aponto essas "aproximações" para, exatamente, poder fazer uma anamnese dos discursos, até porque não há discurso que esteja "em paradigma nenhum", por mais sincrético que seja. Ver, nesse sentido, STRECK, Lenio Luiz. Hermenêutica Jurídica $\mathbf{e}(\mathrm{m})$ crise: uma exploração hermenêutica da construção do Direito. 11 ${ }^{\underline{a}}$ ed. Porto Alegre, RS: Livraria do Advogado, 2014.

${ }^{4}$ Embora ainda mereça certa reflexão o $\S 5^{\circ}$ do art. 157 ao aduzir que "Na localidade onde não houver inscrito no cadastro disponibilizado pelo tribunal, a nomeação do perito é de livre escolha pelo juiz e deverá recair sobre profissional ou órgão técnico ou científico comprovadamente detentor do conhecimento necessário à realização da perícia" (grifo nosso). 
baseados no livre convencimento e na livre apreciação judicial, não é mais possível, em plena democracia, continuar transferindo a resolução dos casos complexos em favor da apreciação subjetiva dos juízes e tribunais. $\mathrm{Na}$ medida em que o Projeto passou a adotar o policentrismo e coparticipação no processo, fica evidente que a abordagem da estrutura do Projeto passou a poder ser lida como um sistema não mais centrado na figura do juiz. As partes assumem especial relevância. Eis o casamento perfeito chamado "coparticipação", com pitadas fortes do policentrismo. E o corolário disso é a retirada do "livre convencimento". O livre convencimento se justificava em face da necessidade de superação da prova tarifada. Filosoficamente, o abandono da fórmula do livre convencimento ou da livre apreciação da prova é corolário do paradigma da intersubjetividade, cuja compreensão é indispensável em tempos de democracia e de autonomia do direito. Dessa forma, a invocação do livre convencimento por parte de juízes e tribunais acarretará, a toda evidência, a nulidade da decisão.

A relatoria da Câmara entendeu muito bem o problema. Não mais se pode elaborar Códigos como se estivéssemos em um paradigma jurídicopolítico no qual o Estado é(ra) visto como inimigo do cidadão. E a partir dessa pergunta e da resposta que se dê a ela que saberemos em que situação nos encontramos, em termos de avanços ou retrocessos democráticos. Parece correto dizer, por exemplo, com Dworkin que uma Constituição como a nossa adota uma "teoria moral" específica: a de que o cidadão tem direitos "contra" o Estado..$^{5} \mathrm{E}$ que, nesse sentido, as cláusulas constitucionais deveriam ser compreendidas não como formulações específicas, mas como restrições, limitações ao Poder Público, sempre favorecendo a preservação dos direitos dos cidadãos. Sendo assim, a nossa pergunta pelo processo jurisdicional democrático começa a ser respondida da seguinte forma: o processo deve ser pautado por direitos e suas disposições têm o sentido de limite, de controle.

O processo (falo aqui do processo jurisdicional, mas essa observação serve também ao processo legislativo) deve servir como mecanismo de controle da produção das decisões judiciais. E por quê? Por pelo menos

${ }^{5}$ Cf. DWORKIN, Ronald. Levando os direitos a sério. Trad. Nelson Boeira. São Paulo, SP: Martins Fontes, 2002, p. 231. 
duas razões: a uma, porque, como cidadão, eu tenho direitos, e, se eu os tenho, eles me devem ser garantidos pelo tribunal, por meio de um processo; a duas, porque, sendo o processo uma questão de democracia, eu devo com ele poder participar da construção das decisões que me atingirão diretamente (de novo: isso serve tanto para o âmbito político como para o jurídico). Somente assim é que farei frente a uma dupla exigência da legitimidade, a mediação entre as autonomias pública e privada. Sou autor e destinatário de um provimento. Por isso é que tenho direito de participar efetivamente do processo.

Há de se perceber que o novo CPC no seu art. 10 adota desde sua redação original a garantia do contraditório como garantia de influência e não surpresa, que deve nortear todo o debate processual, o que já era defendido por parcela da doutrina pátria há bons anos, em especial por Dierle Nunes. ${ }^{6}$ É a partir do art. 10 e do dispositivo que estabelece a coerência e a integridade (art. 926) que temos de ler o restante do CPC/15.

\section{RUMO À SUPERAÇÃO DO VELHO MODELO SOCIAL-PROTAGONISTA? ESPERAMOS QUE SIM}

Ao se fazer uma análise mais detida no $\mathrm{CPC} / 15$, constata-se que ainda há a permanência de reminiscência de velhos paradigmas. Não é fácil acabar com os fantasmas de Oskar Bülow, Menger, Klein, Carnelutti, Couture, Liebman e outros que continuam a atazanar a alma de alguns processualistas brasileiros. Trata-se de uma coagulação de sentidos. Os instrumentalistas - mormente eles - continuam a acreditar que a solução do processo está no "protagonismo judicial". Nisso há um dejà vu, que nos remete ao século XIX.

Com efeito, lemos nas últimas décadas que a interpretação do direito é nitidamente dependente de um sujeito cognoscente: o julgador. E essa questão vem de longe, na verdade, da virada do século XIX para o século XX. Desde então, há um problema filosófico-paradigmático que continua

${ }^{6}$ Cf. NUNES, Dierle José Coelho. O recurso como possibilidade jurídico-discursiva das garantias do contraditório e da ampla defesa. 2003. Dissertação (Mestrado em Direito Processual) - Programa de Pós-Graduação em Direito, Pontifícia Universidade Católica de Minas Gerais, Belo Horizonte, 2003. Nesse sentido, Nelson Nery Junior também defende essa questão mesmo antes da reforma legislativa. Cf. NERY JUNIOR, Nelson. Princípios do Processo na Constituição Federal. 10ª ed. São Paulo, SP: Revista dos Tribunais, 2010, p. 207 e segs. 
presente nos diversos ramos do direito, passados dois séculos, mormente na problemática relacionada à jurisdição e o papel destinado ao juiz especialmente no processo civil. Desde Oskar Von Bülow - questão que também pode ser vista em Anton Menger e Franz Klein -, a relação publicística está lastreada na figura do juiz, como um porta-voz avançado do sentimento jurídico do povo, com poderes para além da lei, tese que viabilizou, na sequência, a Escola do Direito Livre.

Essa aposta solipsista está lastreada no paradigma racionalistasubjetivista que atravessa dois séculos, podendo facilmente ser percebida, na sequência: em Chiovenda, para quem a vontade concreta da lei é aquilo que o juiz afirma ser a vontade concreta da lei; em Carnellutti, de cuja obra se depreende que a jurisdição é "prover", "fazer o que seja necessário"; também em Couture, para o qual, a partir de sua visão intuitiva e subjetivista, entende que o problema da escolha do juiz é, em última análise, o problema da justiça; em Liebman, para quem o juiz, no exercício da jurisdição, é livre de vínculos enquanto intérprete qualificado da lei.

No Brasil, essa dependência do juiz atravessou o século XX (v.g., de Carlos Maximiliano a Paulo Dourado de Gusmão), sendo que tais questões estão presentes na concepção instrumentalista do processo, cujos defensores admitem a existência de escopos metajurídicos, estando permitido ao juiz realizar determinações jurídicas, mesmo que não contidas no direito legislado, com o que o aperfeiçoamento do sistema jurídico dependerá da "boa escolha dos juízes" (sic) e, consequentemente, de seu ("sadio") protagonismo. Por todos, basta remeter o leitor às concepções instrumentalistas, pelas quais juízes e tribunais devem ter "amplo poder de direção" e, com sua sensibilidade, até mesmo devem poder adequar o procedimento à "correta aplicação da técnica processual". ${ }^{7}$

Portanto, não era sem razão que o Projeto do NCPC, que veio do Senado e alterado na Câmara, não abria mão do livre convencimento ou da livre apreciação das provas. Para termos uma ideia de como a opção pelo protagonismo judicial está presente em parcela significativa de nossa doutrina processual, cito as palavras de Cândido Rangel Dinamarco:

Ser sujeito à lei não significa ser preso ao rigor das palavras que os textos contêm, mas ao espírito do direito do seu tempo. Se o texto aparenta apontar para uma solução que não satisfaça ao seu sentimento de justiça, isso significa que provavelmente as palavras do texto ou

${ }^{7}$ Por todos, Cf. BEDAQUE, José Roberto dos Santos. Efetividade do Processo e

Técnica Processual. São Paulo, SP: Malheiros, 2006, especialmente p. 45, 64-65 e 571. 
foram mal empregadas pelo legislador, ou o próprio texto, segundo a mens legislatoris, discrepa dos valores aceitos pela nação no tempo presente. Na medida em que o próprio ordenamento jurídico lhe ofereça (ao juiz) meios para uma interpretação sistemática satisfatória perante o seu senso de justiça, ao afastar-se das aparências verbais do texto e atender aos valores subjacentes à lei, ele (o juiz) estará fazendo cumprir o direito ${ }^{8}$.

Lendo Dinamarco, não tenho receio em afirmar que, acaso se mantivesse a redação original do Projeto, este já nasceria velho, porque favoreceria algo que se pode chamar de Juristocracia (ou Judiciariocracia). Mais do que isso, o Projeto não somente apostava na Judiciariocracia. Na verdade, apostava na Judiciariocracia dos Tribunais Superiores, porque as instâncias inferiores deveriam obedecer detalhadamente - a jurisprudência (direito de precedentes) construída no âmbito dos Tribunais Superiores. Mas, a jurisprudência do andar de cima não teria que seguir também os seus próprios precedentes? Eis aí também uma questão que ajudei a alterar no Projeto, como demonstrarei na sequência.

De todo modo, o Projeto não deveria continuar apostando em atos de ofício, como, por exemplo, o art. 377, pelo qual o juiz pode determinar provas ex officio. De todo modo, não se pode querer, entretanto, um Código perfeito.

\section{EFETIVIDADES QUANTITATIVAS OU QUALITATIVAS? O PROBLEMA DOS POSITIVISMOS}

$\mathrm{O} \mathrm{CPC} / 15$ aposta demasiadamente na figura dos provimentos vinculantes, dos quais um deles é o precedente. Isso pode ser um problema. Mas pode também não ser, dependendo de como esse fenômeno será tratado pela doutrina e pela jurisprudência. Por exemplo, não adianta fazer um "modelo de extermínio de ações repetidas" sem uma teoria decisional! Não tenho nenhum receio em afirmar isso.

${ }^{8}$ Remeto o leitor à crítica que Marcelo Cattoni faz ao Cândido R. Dinamarco. Cf. CATTONI DE OLIVEIRA, Marcelo Andrade. Processo Constitucional. 2ª ed. Belo Horizonte, MG: Pergamum, 2013, p. 217. 
O projeto corre o risco de cair em uma armadilha hermenêutica. Mal aplicada a tese dos precedentes, pode-se cair em uma falácia semântica ou na crença na plenipotenciariedade dos conceitos, como se fosse possível a uma lei, a uma súmula ou a uma ementa jurisprudencial prever todas as hipóteses de aplicação de forma antecipada ${ }^{9}$. Nesse sentido, a tese dos precedentes só funcionará se adotar uma postura hermenêutica, aquilo que se denomina de applicatio a partir de Gadamer e que foi retrabalhada por mim na Crítica Hermenêutica do Direito. ${ }^{10}$

Não se pode simplesmente transportar a doutrina da common law para o nosso Código de Processo Civil. ${ }^{11}$ Se não superarmos as posturas positivistas (falo dos diversos positivismos, que, como se sabe, são muitos), corremos o risco de uma importação indevida e desastrosa. Explico: sem um olhar hermenêutico, o CPC/15 corre o risco de acumular dois positivismos: o velho exegetismo, pela aposta em uma espécie de conceptualização (saudades da Bregriffjurisprudenz? ${ }^{12}$ ), e no positivismo pós-exegético de perfil normativista, porque aposta no poder discricionário dos juízes (eis aí o protagonismo judicial).

Ao acabar com o livre convencimento, o risco desse segundo problema diminui. Porém, há que se ter uma vigilância epistêmica, para evitar que a cotidianidade das práticas do Judiciário repristine o livre convencimento e, portanto, as posturas decisionistas. O judiciário assim, "naturaliza" o não cumprimento. Depois os advogados se acostumam. Já nem sentem o látego. A naturalização é um fenômeno que faz com que, mais tarde, alguém diga: mas isso sempre foi assim.

Veja-se a pesquisa do termo "livre convencimento", deixando de fora o 'motivado' que aparecem em ementas. Claque, ao lado desses descumprimentos, há também a não aplicação dos incisos do parágrafo primeiro do artigo 489. As notícias não são animadoras. Da data de 18 de março até 4 de maio - TJ-SP - 114 menções em ementas de processo civil

${ }^{9}$ Não devemos esquecer que a Constituição estabelece que os juízes e Tribunais julgarão causas... Não está escrito em lugar nenhum que juízes e tribunais julgarão teses ou enunciados assertóricos. Ao que se pode perceber, o Projeto do novo CPC aposta muito mais na construção de teses (súmulas, enunciados, ementários resultantes de incidentes de unificação jurisprudencial) do que na resolução de causas. Essa denúncia já é feita, de há muito, por autores como Alexandre Bahia. ${ }^{10}$ STRECK, Lenio Luiz. Lições de Crítica Hermenêutica do Direito. Porto Alegre, RS: Livraria do Advogado, 2014, p. 82-91.

${ }^{11}$ Cf. STRECK, Lenio Luiz; ABBOUD, Georges. O que é isto: o precedente judicial e as súmulas vinculantes? Porto Alegre, RS: Livraria do Advogado, 2013.

12 A Jurisprudência dos Conceitos foi uma forma de positivismo exegético predominante na Alemanha do século XIX. 
ou trabalhista de sua competência; TJ-RJ - 264 (de todo o período de 2016 - não há como fatiar por meses); TJ-MG - 20 menções ao livre convencimento; TRF-4 - 44 menções e, por fim, e por fim, o TJ-RS com 483 registros em ementas na seção cível do TJ-RS (incluindo turmas recursais). Nos demais, os números podem ser menores por não incluir as turmas recursais. Atenção: também estão presentes em vários desses julgados violações a outros dispositivos do novo CPC. Desse modo, a própria doutrina, se mal compreender esta nova realidade, poderá contribuir para enterrar o CPC/15.

\section{SERÍAMOS UMA CORRUPTELA DO COMMON LAW? O CPC E OS "PRECEDENTES"}

A redação original dos artigos 520 e seguintes do Projeto dava a nítida impressão de que nosso sistema jurídico não é da família do civil law. Vejamos: o art. 520 afirmava que, "Os tribunais devem uniformizar sua jurisprudência e mantê-la estável" e o art. 522 estabelecia que, "Para os fins deste Código, considera-se julgamento de casos repetitivos: I - o do incidente de resolução de demandas repetitivas; II - o dos recursos especial e extraordinário repetitivos".

Esses dispositivos mereceram minha contundente crítica. A questão mais grave referia-se a commonlização que estes representavam. Poucos juristas se davam conta que, com o Projeto, qualitativamente, havia uma grande chance de perda no nosso sistema decisório, porque de um lado, este Projeto não combatia a possibilidade de o STJ e o STF continuarem a decidir discricionariamente, e de outro ele atribuía, irrefletidamente, efeito vinculante para a quase totalidade das decisões desses tribunais (inclusive dos obter dictum).

Sendo mais claro: o Projeto trazia um modelo de "como-seguirprecedentes"... Só que esse modelo só servia para as instâncias inferiores. Não havia nada que indicasse que quem faz o precedente devesse sofrer algum controle. Por que quem elabora os precedentes mais relevantes não precisa seguir os caminhos que as instâncias inferiores devem seguir?

Por isso, um ponto importantíssimo foi a aceitação por parte do relator de outra sugestão de minha lavra, que contou com o auxílio de Dierle Nunes, qual seja, a introdução de um novo parágrafo $\S 1^{\circ}$ ao artigo 521 do Projeto. Por esse novo preceito, "[...] O órgão jurisdicional observará o disposto no artigo 10 e no artigo 499, parágrafo 1 을 na formação e aplicação do precedente judicial".

Trata-se da adoção do contraditório como garantia de influência e não 
surpresa. Vejamos o que diz o artigo 10 de que fala o aludido parágrafo $1^{\circ} .:$ "Art. 10. Em qualquer grau de jurisdição, o órgão jurisdicional não pode decidir com base em fundamento a respeito do qual não se tenha oportunizado manifestação das partes, ainda que se trate de matéria apreciável de ofício". E o que diz o artigo 489? São elementos essenciais da sentença:

I - o relatório, que conterá os nomes das partes, a identificação do caso, com a suma do pedido e da contestação, e o registro das principais ocorrências havidas no andamento do processo;

II - os fundamentos, em que o juiz analisará as questões de fato e de direito;

III - o dispositivo, em que o juiz resolverá as questões principais que as partes lhe submeterem.

Parágrafo $1^{\mathrm{o}}$ Não se considera fundamentada qualquer decisão judicial, seja ela interlocutória, sentença ou acórdão, que:

I - se limitar à indicação, à reprodução ou à paráfrase de ato normativo, sem explicar sua relação com a causa ou a questão decidida;

II - empregar conceitos jurídicos indeterminados, sem explicar o motivo concreto de sua incidência no caso;

III - invocar motivos que se prestariam a justificar qualquer outra decisão;

IV - não enfrentar todos os argumentos deduzidos no processo capazes de, em tese, infirmar a conclusão adotada pelo julgador;

V - se limitar a invocar precedente ou enunciado de súmula, sem identificar seus fundamentos determinantes nem demonstrar que o caso sob julgamento se ajusta àqueles fundamentos;

VI - deixar de seguir enunciado de súmula, jurisprudência ou precedente invocado pela parte, sem demonstrar a existência de distinção no caso em julgamento ou a superação do entendimento.

Parágrafo $2^{\mathrm{o}}$ No caso de colisão entre normas, o órgão jurisdicional deve justificar o objeto e os critérios gerais da ponderação efetuada, enunciando as razões que autorizam a interferência na norma afastada e as premissas fáticas que fundamentam a conclusão.

Parágrafo $3^{\text {o }}$ A decisão judicial deve ser interpretada a partir da conjugação de todos os seus elementos e em conformidade 
com o princípio da boa-fé.

Vejamos: a crítica que eu sustentava, de que apenas o "andar de baixo" estava obrigado a cumprir a criteriologia e apenas estes (juízes e tribunais não superiores) estavam obrigados a seguir a jurisprudência, agora está sanada, porque o "andar de cima" está jungido a sua própria jurisprudência. E não poderá mudá-la a seu talante. Uma conquista hermenêutica e democrática.

Outro avanço do presente projeto no tocante ao respeito aos precedentes trata-se da possibilidade de julgamento liminar de improcedência. À redação atual deste instituto, assim aduz:

Art. 285-A. Quando a matéria controvertida for unicamente de direito e no juízo já houver sido proferida sentença de total improcedência em outros casos idênticos, poderá ser dispensada a citação e proferida sentença, reproduzindo-se o teor da anteriormente prolatada. [...] (grifo nosso)

Pois bem. O novel art. 332, por sua vez, não permite ao juiz que decida liminarmente com esteio em uma decisão de improcedência por ele anteriormente proferida - utilizando-se de um mero recurso de "cópia e cola" -, mas, ao contrário, passa a exigir que a fundamentação seja feita em súmulas, acórdãos de recursos repetitivos, incidentes de resolução de demandas repetitivas, assunção de competência ou em frontal contradição à norma jurídica extraída de ato normativo.

Outro ponto importante - e que constava em minha crítica - era sobre a obrigação dos tribunais manterem a estabilidade da jurisprudência. Dizia eu, de forma contundente, que a estabilidade é diferente da integridade e da coerência do Direito, pois a "estabilidade" é um conceito autorreferente, isto é, numa relação direta com os julgados anteriores. Já a integridade e a coerência guardam um substrato éticopolítico em sua concretização, isto é, são dotadas de consciência histórica e consideram a facticidade do caso. Pois muito bem.

A inteligência do relator e de Fredie Didier foram cruciais para o acatamento dessa minha sugestão de caráter dworkiniano, simples, mas que poderá mudar a história da aplicação do direito de terrae brasilis: trata-se da exigência de coerência e integridade, ao lado da estabilidade. Explico: significa dizer que, em casos semelhantes, deve-se proporcionar a garantia da isonômica aplicação principiológica.

Haverá coerência se os mesmos princípios que foram aplicados nas decisões o forem para os casos idênticos; mas, mais do que isto, estará 
assegurada a integridade do direito a partir da força normativa da Constituição. A coerência assegura a igualdade, isto é, que os diversos casos terão a igual consideração por parte dos juízes. Isso somente pode ser alcançado através de um holismo interpretativo, constituído a partir do círculo hermenêutico. Já a integridade é duplamente composta, conforme Dworkin: um princípio legislativo, que pede aos legisladores que tentem tornar o conjunto de leis moralmente coerente, e um princípio jurisdicional, que demanda que a lei, tanto quanto possível, seja vista como coerente nesse sentido. A integridade exige que os juízes construam seus argumentos de forma integrada ao conjunto do direito. Trata-se de uma garantia contra arbitrariedades interpretativas. A integridade limita a ação dos juízes; mais do que isso, coloca efetivos freios, através dessas comunidades de princípios, às atitudes solipsistas-voluntaristas. A integridade é uma forma de virtude política. A integridade significa rechaçar a tentação da discricionariedade.

\section{OS EMBARGOS DECLARATÓRIOS CONVIVERÃO COM O FIM DO "LIVRE CONVENCIMENTO"?}

Se eu tivesse que escolher um instituto que represente simbolicamente o "estado de natureza hermenêutico" (homenagem a Hobbes), escolheria os embargos declaratórios. Vejamos já pelo nome: "embargos". Imaginese uma "obra embargada"... Assim é uma decisão judicial ou acórdão que sofre "embargos". Tratar-se-ia, pois, de algo com gravíssimas consequências. No restante do direito, quando se fala em "embargo" é porque algum obstáculo é posto à livre disposição de algum bem. Mas, no âmbito do processo (civil e penal), a palavra "embargo(s)" passou a sofrer de "anemia significativa". E, consequentemente, ocorreu a banalização de uso.

Trata-se, pois, de uma virose epistêmica que assola o direito, produto da vulgata do voluntarismo que assaltou o direito. Isso vem de longe. Perguntava de há muito: como é possível que um Código de Processo Civil (também o de processo penal) admita que um juiz ou tribunal, agentes políticos do Estado, produzam decisões (sentenças e acórdãos) omissas, obscuras ou contraditórias? Mas, pior: como é possível que, passados tantos anos e tantas teorias, um novo Código de Processo Civil continue a apostar nesse artifício anti-hermenêutico?

Ora, se a fundamentação é um dever fundamental do juiz e um direito igualmente fundamental do utente, de que modo se pode admitir que sejam lançadas/promulgadas sentenças com esses vícios? Só para 
registrar: a Corte Europeia dos Direitos Humanos ${ }^{13}$ declarou, de há muito, que a fundamentação, antes de um dever dos juízes e tribunais, é um direito fundamental do cidadão. Fundamentação frágil gera nulidade.

Parece evidente que a previsão da possibilidade de um juiz ou tribunal produzir decisões omissas, contraditórias ou obscuras fere frontalmente o art. 93, IX, da Constituição, além dos dispositivos que tratam do devido processo legal e do contraditório. Absolutamente inconstitucional! Neste ponto, o CPC/15 estabelece exatamente isso em capítulo próprio (V), artigos 1035 e segs. Pior, desta vez, ampliou seu espectro de aplicação, acolhendo a criação pretoriana ao abarcar no texto a possibilidade de o juiz corrigir erros materiais (v.g., erros de digitação) e, ainda, no bojo de decisões interlocutórias.

Sempre pensei que uma decisão omissa (vejam no dicionário o significa a palavra "omissão"...) seria nula, írrita, nenhuma. Igualmente, parece evidente que uma sentença contraditória (portanto, que fere o raciocínio lógico) também deveria ser nula, írrita, nenhuma. Uma decisão obscura demonstra obscuridade de raciocínio e está longe, portanto, daquilo que o próprio CPC estipula como requisito da sentença.

Por certo - e não me tomem por ingênuo - a incorporação dos embargos no sistema processual brasileiro acabou por gerar um subproduto que, no contexto atual, confere certa importância (pragmática) para o instituto. Isso é óbvio. Até mesmo não se nega que, em casos limitados, uma decisão poderia demandar um esclarecimento. Mas não do modo como hoje se age. O que quero dizer com isso? Refirome ao fato de que, a morosidade da justiça, a dificuldade de tramitação de inúmeros recursos que seriam aplicáveis às hipóteses de sentenças nulas (por ausência ou insuficiência de fundamentação, vale dizer que, sentenças omissas, obscuras ou contraditórias são, ao final, sentenças com fundamentação insuficiente, portanto, nulas), faz com que os embargos sejam instrumentos úteis para sanar erros materiais cometidos pelo juízo a partir de uma intervenção "cirurgicamente" mais precisa no desenrolar

${ }^{13}$ É a proibição do lack of reasoning, pela interpretação do processo equitativo previsto no artigo 6 ${ }^{\circ}$ da Convenção Europeia dos Direitos do Homem. Vejam-se os julgados da Corte Européia de Direitos do Homem: H. v. Belgium (1987) e Hiro Balani v. Spain (1994). Cf. H. v. Belgium, A127-B (1987). Disponível em:

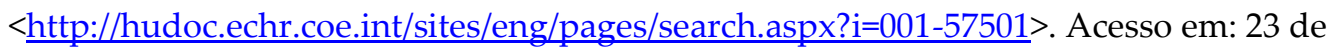
maio de 2014; Hiro Balani v. Spain, A303-B (1994). Disponível em: $<$ http://hudoc.echr.coe.int/sites/eng/pages/search.aspx?i=0 01-57910>. Acesso em: 23 de maio de 2014. 
processual.

Só que isso acaba por gerar um círculo vicioso progressivo: na medida em que temos embargos, temos mais recursos no Judiciário; se temos mais recursos, temos mais trabalho; se temos mais trabalho e não aumentamos a estrutura humana/funcional que opera com tudo isso, temos mais morosidade... Enfim, no fundo, os embargos, no lugar de remédios, acabam por se constituir como parte da causa da doença.

Quero dizer que além de a própria existência dos embargos de declaração ser algo, digamos assim, estupefaciente e bizarro, também a sua operacionalidade em terrae brasilis deixa muito a desejar. Acaba dando ao processo contornos, para dizer o menos, de um jogo (não raro, de cartas marcadas!).

Com a exigência de que os julgamentos tenham que manter a coerência e a integridade e diante do fim do livre convencimento, não serão mais toleradas decisões genéricas como aquelas que dizem: “O juiz, na linha de precedentes do STF, não está obrigado a responder a todas as questões articuladas pelas partes. As razões de meu convencimento são suficientemente claras. Rejeito os embargos". Decisão desse jaez deverá receber a pecha de nulidade. Simples, pois.

Bem compreendido isso, penso que poderemos avançar, mesmo que o Projeto tenha mantido os Embargos de Declaração. Só que, agora, os embargos devem ser lidos à luz dos artigos 10 e 499. Elementar! Nunca mais veremos feitos como o RE. 222.752, verbis:

Re 222752 - Recurso Extraordinário

Recurso Extraordinário

1. Emb. Decl. No Recurso Extraordinário

2. Emb. Decl. Nos Emb. Decl. No Recurso Extraordinário

3. Emb. Decl. Nos Emb. Decl. Nos Emb. Decl. No Recurso Extraordinário

4. Emb. Decl. Nos Emb. Decl. Nos Emb. Decl. Nos Emb. Decl. No Recurso Extraordinário

5. Ag. Reg. Nos Emb.Decl. Nos Emb.Decl. Nos Emb.Decl. Nos Emb.Decl. No Recurso Extraordinário

6. Ag. Reg. No Ag. Reg. Nos Emb. Decl. Nos Emb. Decl. Nos Emb. Decl. Nos Emb. Decl. No Recurso Extraordinário

7. Ag. Reg. No Ag. Reg. No Ag. Reg. Nos Emb. Decl. Nos Emb. Decl. Nos Emb. Decl. Nos Emb. Decl. No Recurso Extraordinário

8. Emb. Decl. No Ag. Reg. No Ag. Reg. Nos Emb. Decl. Nos Emb. Decl. Nos Emb. Decl. Nos Emb. Decl. No 
Recurso Extraordinário

(ipsis literis; pontuação do original do respectivo site; apenas coloquei a numeração de 1 a 8)

Assume relevância o voto do Min. Gilmar Mendes no MS 24.268/04", em que ele promove, com base na jurisprudência do Tribunal Constitucional alemão, uma autêntica homenagem ao direito-dever fundamental de as decisões serem fundamentadas. Penso que com essa decisão já poderíamos derrubar essa virose epistêmica representada pelos embargos declaratórios.

De acordo com a referida decisão, o cidadão que entra em juízo tem:

a) direito de informação (Recht auf Information), que obriga o órgão julgador a informar a parte contrária dos atos praticados no processo e sobre os elementos dele constantes;

b) direito de manifestação (Recht auf Äusserung), que assegura ao defensor a possibilidade de manifestar-se oralmente ou por escrito sobre os elementos fáticos e jurídicos constantes do processo;

c) direito de ver seus argumentos considerados (Rech tauf Berücksichtigung), que exige do julgador capacidade, apreensão e isenção de ânimo (Aufnahmefähigkeitund Aufnahmebereitschaft) para contemplar as razões apresentadas.

O mesmo voto do Min. Gilmar Mendes incorpora, ainda, a doutrina de Dürig/Assmann, ao sustentar que o dever de conferir atenção ao direito das partes não envolve apenas a obrigação de tomar conhecimento (Kenntnisnahmeplicht), mas também a de considerar, séria e detidamente, as razões apresentadas (Erwägungsplicht).

Penso que esse tipo de decisão, na esteira dos artigos 10 e 926 do $\mathrm{CPC} / 15$, pode ser um antídoto contra a banalização dos embargos. Aliás, em Comentários à Constituição do Brasil, na especificidade do art. 93, IX, deixamos claro, o Min. Gilmar Mendes e eu, que a obrigatoriedade da fundamentação é, assim, corolário do Estado Democrático de Direito. Mais do que uma obrigação do magistrado ou do Tribunal, trata-se de um direito fundamental do cidadão, de onde se pode afirmar que, em

${ }_{14}$ Para uma análise mais detalhada do voto, Cf., STRECK, Lenio Luiz. Verdade e

Consenso: Constituições, Hermenêutica e Teorias Discursivas. $4^{a ̣}$ ed. São Paulo, SP:

Saraiva, 2011, p. 601-602. 
determinadas circunstâncias e em certos casos, uma decisão, antes de ser atacada por embargos declaratórios, é nula por violação do inciso IX do art. $93 .{ }^{15}$

\section{OS PRECEDENTES E A INCINDIBILIDADE ENTRE QUESTÃO-DE- FATO E QUESTÃO-DE-DIREITO}

Penso que o Código de Processo Civil/15 poderia ter um avanço maior. Um dos motes ainda não superados trata-se da tentativa de separar questões de fato de questões de direito.

O Código de Processo Civil de 1973 já incorria neste mal entendido quando, v.g., aduzia ser possível a decisão liminar de improcedência quando a matéria controvertida for unicamente de direito (art. 285-A). Assim também, quando previa o julgamento direto do mérito pelo Tribunal, em apelação de processo extinto sem julgamento do mérito, se a causa versar questão exclusivamente de direito (art. 515, §3으. . Ainda, quando no âmbito dos recursos repetitivos diante do STJ aduz que só podem ser suspensos aqueles com fundamento em idêntica questão de direito (art. 543-C, caput).

Embora de maneira escamoteada, esta tentativa de "lógica objetivadora" permeava diversas técnicas de filtragem e de vinculação, como a negativa de recursos manifestamente inadmissíveis (art. 557, caput e $\S 1^{\circ}$ ), o sobrestamento de recursos extraordinários (art. 543-B), a repercussão geral (art. 543-A), e a súmula vinculante (Lei 11.417/06).

O Código de Processo Civil/15 abusa da expressão questão de direito, fazendo referência a uma possível questão que não fosse relacionada a um fato. Podem ser citados como exemplo o julgamento de casos repetitivos (art. 928, parágrafo único), o incidente de assunção de competência (art. 947, caput), o incidente de resolução de demandas repetitivas (art. 976) e o julgamento dos recursos extraordinários e especial repetitivos (art. 1.036, caput).

Todavia, impende ressaltar que sob uma perspectiva hermenêutica é impossível fazer tal distinção, porquanto a interpretação do direito é sempre uma aplicação (applicatio), e por isso, pressupõe o mundo prático. E, ainda que alguém não tenha dada por superada a relação sujeitoobjeto, tanto o fato quanto o direito fazem parte da causa de pedir, um

${ }^{15}$ MENDES, Gilmar Ferreira; STRECK, Lenio Luiz. Art. 93, B - Comentários. In: CANOTILHO, J. J. Gomes et al. (Coords.). Comentários à Constituição do Brasil. São Paulo, SP: Saraiva/Almedina, 2013, p. 1325. 
dos elementos (indispensáveis) da ação. Ora, os fatos só terão importância para o direito se forem fatos juridicamente relevantes - $\mathrm{e}$, daí, a necessária imbricação entre questões de fato e questão de direito, o que, em linguagem hermenêutica, denominamos de diferença ontológica.

Neste sentido, leciona Castanheira Neves:

E assim temos de concluir, quanto a este último sentido, que o direito não pode prescindir do facto e que o facto não pode prescindir do direito. Na verdade, se por um lado não há validade que não seja validade de algo, e de algo que relativamente a essa intenção fundamentalmente se ofereça na contingência da facticidade, também a validade jurídica não poderá de ter um contingente e material sujeito-objecto a predicar, e no qual se cumpra - o predicado não prescinde do sujeito e terá nele justamente de se afirmar predicado, uma questio juris é sempre a questio facti. Por outro lado, sendo os factos de um problema concreto de direito o objeto intencional da respectiva questão-de-fato, e por esta são determinados, não é menos certo que também eles não têm sentido sem referência à questão-de-direito, pois uma quaestio facti é necessariamente a quaestio facti de uma certa quaestio juris. ${ }^{16}$

Assim, verifica-se da redação do novo Código padece de uma impropriedade técnica: quando o legislador refere-se à questão de direito (ou expressões congêneres) não quer, na verdade, se reportar a questões que não sejam munidas de questões de fato, mas sim causas que não demandem dilação probatória, em especial de natureza testemunhal e/ou pericial. Assim que deveremos ler esse texto.

A título exemplificativo, podemos pensar nas demandas que buscam a devolução de expurgos inflacionários decorrentes da aplicação de índices inferiores aos devidos sobre a caderneta de poupança no início da década de 1990. Neste caso, é óbvio que aquele que peticiona em juízo o faz porque à época era titular de uma caderneta de poupança. Também é evidente que deverá provar esta condição com a juntada dos extratos respectivos, mormente para que se torne possível o cálculo do valor devido.

${ }^{16}$ NEVES, A. Castanheira. A distinção entre a questão-de-facto e a questão-de-direito. In: A. Castanheira Neves. Digesta: escritos acerca do pensamento jurídico, da sua metodologia e outros. Vol. 1. Coimbra: Coimbra Editora, 1995, p. 511. 
Nesta hipótese, os documentos juntados são indispensáveis para o processamento da demanda, sob pena de indeferimento da petição inicial. Por outro lado, a causa proposta não exige maior dilação probatória: não é necessário ouvir testemunhas para afirmação da titularidade da conta-corrente, tampouco se torna necessária perícia grafotécnica. Assim, todas as provas necessárias ao julgamento da demanda já foram colhidas e, por isso, torna-se possível aplicar aos "casos similares" - e que também não dependem de prova - as mais variadas "técnicas de objetivação" do processo (súmula vinculante, julgamento de demandas repetitivas, incidente de assunção de competência, dentre outros).

Diferentemente ocorre, por exemplo, em demandas em que a prova documental inicial não se faz suficiente ao julgamento da demanda. Nestas hipóteses, será indispensável dilação probatória e, como cada caso tona-se um caso particular em razão das peculiaridades das provas a serem colhidas, jamais poderá ser feito um juízo de similaridade.

Portanto, podemos concluir que a "lógica" dos precedentes não pode determinar como parâmetro de escolha do objeto de sua aplicação a distinção questão-de-direito, como se fosse possível cindi-la de uma pretensa questão-de-fato. Por isso, a redação do novo Código deveria ser mais clara e precisa utilizando-se da expressão "questão que não demande dilação probatória" (ou algo do gênero) no lugar de "questão de direito". De todo modo, também aqui a interpretação da ossatura do Código, se a doutrina efetivamente vier a doutrinar, levará a esse sentido. Um texto jurídico não se interpreta por partes. Por isso, o círculo hermenêutico: do todo para a parte, da parte para o todo.

\section{CONSIDERAÇÕES FINAIS}

Nunca estive de má vontade com o CPC/15. Tudo o que escrevi foi para criticar o instrumentalismo processual e seus efeitos colaterais, presentes até que o Relator, Dep. Paulo Teixeira, assumisse, corajosamente, a tese de que havia algo a mais para ser tratado no Projeto. Esse plus dizia respeito aos paradigmas filosóficos e à necessidade de controlar as decisões judiciais.

Um dos pontos centrais a favor do CPC/15 é o abandono do livre convencimento e da livre apreciação da prova. Simbolicamente isso representa o desejo de mudar. E saltar paradigmaticamente. Com efeito, seja do ponto de vista normativo, seja do ponto de vista performativo, "livre convencimento" (ou livre apreciação da prova) não é o mesmo que "decisão fundamentada". Isso porque da perspectiva normativa do 
princípio que exige a fundamentação das decisões, o juiz não tem a opção para se convencer por qualquer motivo, uma espécie de discricionariedade em sentido fraco que seja, mas deve explicitar com base em que razões, que devem ser intersubjetivamente sustentáveis, ele decidiu desta e não daquela maneira, conforme bem diz Marcelo Cattoni. É claro que nenhuma decisão se dá no vácuo, mas num contexto históricoinstitucional. Todavia, na sua fundamentação, o juiz deve posicionar-se explicitamente em relação a este contexto institucional.

Realmente, ser correto e decidir de forma imparcial não é uma tarefa fácil. Exige exercício prático, senso de dever, capacidade de se adotar uma atitude reflexiva em relação às próprias pré-compreensões, garantia de comparticipação dos destinatários da decisão no processo deliberativo, aprendizado institucional e debate público. O resto é desculpa para se fugir de responsabilidades.

O Projeto do novo CPC, ao apostar no livre convencimento (com esse nome ou outro qualquer) fazia uma leitura idealista projetando uma dicotomia entre normas e fatos, uma perspectiva monológica e solipsista da questão que se esquece de que a normatividade é uma construção intersubjetiva interna à realidade, embora não se deixe reduzir a uma mera força do factual. Ora, do ponto de vista hermenêutico-crítico, a "realidade" não é um obstáculo, mas é constitutiva, reflexivamente, do processo hermenêutico de concretização da normatividade. Basta pensar em autores como Friedrich Müller ou Ronald Dworkin, por exemplo. Até porque "a realidade em si" não existe, a realidade é uma construção hermenêutica; o que há são tradições, paradigmas, précompreensões, permanentemente em disputa e em conflito, dessa e nessa mesma realidade, em face do horizonte de uma história efectual enquanto aprendizado social de longo prazo, cujo sentido permanece também em aberto.

Além disso, falar em livre convencimento, sobretudo quando sabemos que nenhum sentido se constrói fora deste "espaço" hermenêutico, é correr o risco de se adotar uma atitude performativa irreflexiva em relação a essas tradições, paradigmas e pré-compreensões; é correr o risco de perpetuar, portanto, preconceitos e práticas institucionais com as quais se pretendia romper exatamente por meio de uma reforma legislativa.

Alvíssaras, portanto. Outro ponto de fundamental importância diz com a obrigatoriedade de a jurisprudência adotar os princípios da coerência e da integridade, problemática que levantei já nas $3^{\underline{a}}, 4^{\underline{a}}$ e $5^{\underline{a}}$. edições de Verdade e Consenso. O Código abandona a simplicidade da exigência da "estabilidade" e passa a exigir coerência e integridade. Isso, aliado ao art. 10 do projeto e à expunção do livre convencimento, há de dar um salto para além do velho instrumentalismo das tentações do fator 
Oskar Büllow (social protagonismo fruto de uma visão solipsista do processo - e do mundo).

Ficaram ainda alguns pontos que poderiam ter sido melhor desenvolvidos, como o problema do agir de ofício do juiz (arts. 2; 139, IV; 337 e 536), que se apresenta contraditório ao que dispõe o restante do Código. Também o poder cautelar do juiz representa um passo atrás, isto é, um passo na direção do velho social-protagonismo, incoerente, portanto, com os ditames dos artigos 10 e 926 e seguintes do Código.

De todo modo, creio que do projeto e sua complexidade podem ser retirados alguns princípios norteadores do novo Código, como o da necessidade de manter a coerência e a integridade da jurisprudência (incluídos os precedentes), a vedação do livre convencimento, o que implica um menor protagonismo e a necessidade da adoção do paradigma da intersubjetividade, ou seja, a subjetividade do juiz deve ser suspensa e controlada pela intersubjetividade estruturante do direito. Essa é a holding do novo "sistema". Sem compreendê-lo, corremos o risco de fazer uma revolução à avessas. Raciocínios pequeno-gnosiológicos ainda assentados nos paradigmas objetivistas ou subjetivistas (ou de suas vulgatas voluntaristas) podem, rapidamente, provocar a derrocada de uma boa ideia.

\section{REFERÊNCIAS}

BEDAQUE, José Roberto dos Santos. Efetividade do Processo e Técnica

Processual. São Paulo, SP: Malheiros, 2006.

CARVALHO DIAS, Ronaldo Brêtas de. Projeto do novo Código de Processo Civil aprovado pelo Senado: exame técnico e constitucional. In: Fernando Rossi et al. (Orgs.). O Futuro do Processo Civil no Brasil: uma Análise Crítica ao Projeto do Novo CPC. Belo Horizonte, MG: Fórum, 2011.

CATTONI DE OLIVEIRA, Marcelo Andrade. Processo Constitucional. $2^{a}$ ed. Belo Horizonte, MG: Pergamum, 2013.

DELFINO, Lúcio. A paradoxal decisão por equidade no Estado Democrático de Direito: apontamentos sobre o “Relatório Paulo 
Teixeira". In: Alexandre Freire et al. (Orgs.). Novas Tendências do Processo Civil. Estudos sobre o Projeto do Novo Código de Processo Civil: Vol. 3. Salvador, BA: Editora JusPodivm, 2014.

DWORKIN, Ronald. Levando os direitos a sério. Trad. Nelson Boeira. São Paulo, SP: Martins Fontes, 2002.

MENDES, Gilmar Ferreira; STRECK, Lenio Luiz. Art. 93, B Comentários. In: CANOTILHO, J. J. Gomes et al. (Coords.). Comentários à Constituição do Brasil. São Paulo, SP: Saraiva/Almedina, 2013.

NERY JUNIOR, Nelson. Princípios do Processo na Constituição Federal. 10ª ed. São Paulo, SP: Revista dos Tribunais, 2010.

NEVES, A. Castanheira. A distinção entre a questão-de-facto e a questão-de-direito. In: A. Castanheira Neves. Digesta: escritos acerca do pensamento jurídico, da sua metodologia e outros. Vol. 1. Coimbra: Coimbra Editora, 1995.

NUNES, Dierle José Coelho. $\mathbf{O}$ recurso como possibilidade jurídicodiscursiva das garantias do contraditório e da ampla defesa. 2003. Dissertação (Mestrado em Direito Processual) - Programa de PósGraduação em Direito, Pontifícia Universidade Católica de Minas Gerais, Belo Horizonte, 2003.

. O princípio do contraditório. Revista Síntese de Direito Civil e Processo Civil, Vol. 5, 29, 2004.

STRECK, Lenio Luiz; ABBOUD, Georges. O que é isto: o precedente judicial e as súmulas vinculantes? Porto Alegre, RS: Livraria do Advogado, 2013. 
STRECK, Lenio Luiz. Verdade e Consenso: Constituições, Hermenêutica e Teorias Discursivas. $4^{a}$ ed. São Paulo, SP: Saraiva, 2011.

. Hermenêutica Jurídica e(m) crise: uma exploração

hermenêutica da construção do Direito. $11^{\underline{a}}$ ed. Porto Alegre, RS:

Livraria do Advogado, 2014.

. Novo CPC decreta a morte da lei. Viva o common law!

Disponível em: $<$ http://www.conjur.com.br/2013-set-12/senso-incomumcpc-decreta-morte-lei-viva-common-law $>$. Acesso em: 23 de maio de 2014.

. Lições de Crítica Hermenêutica do Direito. Porto Alegre, RS:

Livraria do Advogado, 2014.

Uma Análise Hermenêutica dos Avanços Trazidos pelo Novo CPC A Hermeneutic Analysis of the New Civil Procedure Code Advances

Submetido em: 2016-05-24

Aceito em: 2016-07-10 